\title{
Identifikasi Morfologi Aksesi Srikaya (Annona squamosa) di Gedangsari Gunungkidul
}

\section{The Morphological Identification of Accession Sugar-Apple (Annona squamosa) in Gedangsari Gunungkidul}

\author{
Danang Setiono ${ }^{1)}$, Parjanto ${ }^{2)}$, Djati Waluyo Djoar ${ }^{2)}$
}

\begin{abstract}
The purpose of this study to determine the morphological characteristics and variability of planting sugar apple Gedangsari, Gunungkidul, Yogyakarta. Identify the morphological characteristics conducted on 36 plant samples (36 accessions) based method on stratified sampling and purposive sampling. The data were analyzed descriptively and clustering analysis. The results of the research showed that sugar-apple had pyramida canopy shape, plant height of $264 \pm 525 \mathrm{~cm}$, oblongus leaves type, integer leaves margins, acuminatus leaves tip form, base acutus leaves, petiole cylindrical shape, dark green petiole, dark green color of the upper surface leaves, faded green color of the lower surface, leaves length $16.06 \pm 8.23 \mathrm{~cm}$, leaves width $3,73 \pm 6,9 \mathrm{~cm}$, leaves area $24,28 \pm 85,71 \mathrm{~cm}^{2}$, round shaped of rod, patens branching pattern, stem circumference $17,5 \pm 38 \mathrm{~cm}$, axillary flos of flower layout, having 3 petals, whitish green of flower color, is cordate and round shape of fruit, fruit weight of $83,03 \pm 180,3 \mathrm{~g}$, fruit circumference $22,4 \pm 19,36 \mathrm{~cm}$, flesh thick $1,73 \pm 3,66 \mathrm{~mm}$, whitish green and green of fruit color, the total amount of fruit scales $70 \pm 104,66$, and the value of PTT between 18-29 ${ }^{\circ}$ brix, blunt shape of fruit scales, ellipsoid shape of seeds, number seeds $7 \pm 70,66$ and total seed weight $2,3 \pm 19,86 \mathrm{~g}$. There were variability include leaves length, leaves width, leaves area, stem girth, fruit weight, fruit girth, fruit flesh thickness, number of fruit scales, PTT values and fruit shape and the fruit skin's color. The result of clustering analysis showed that similarity coefficient between the accessions was $66 \%$.
\end{abstract}

Keywords : sugar-apple, morphological characters, variability

\section{PENDAHULUAN}

Indonesia merupakan negara dengan keanekaragaman plasma nutfah yang tinggi, salah satunya terlihat dari banyaknya tanaman buah tropis yang tumbuh dan berkembang (BPTP Jatim 2011). Plasma nutfah bermanfaat sebegai penyedia materi genetik dalam usaha perbaikan sifat tanaman. Srikaya merupakan salah satu kekayaan plasma nutfah Indonesia yang berpotensi sebagai komoditas hortikultura unggulan karena kandungan gizi yang tinggi (Kementan 2012).

Srikaya termasuk tanaman buah istimewa dikarenakan kandungan gizi buahnya yang tinggi dan hampir semua bagian tanaman mempunyai manfaat (Kementan 2012). Srikaya mengandung antioksidan seperti vitamin $C$ yang membantu melawan radikal bebas dalam tubuh, vitamin A yang bermanfaat untuk menjaga kulit, kesehatan rambut, serta meningkatkan fungsi mata. Kalium dan Magnesium yang terkandung dalam buah juga mencegah penyakit jantung.

Srikaya merupakan buah lokal yang memiliki sebaran daerah tumbuh yang luas, namun belum ada data pasti daerah penyebarannya (Alex 2011). Di pulau jawa diketahui tumbuh di daerah Jakarta dan sekitarnya, tangerang, sukabumi, cirebon, jalur Subang-Indramayu, Surakarta, Yogyakarta dan Kudus. Sebaran daerah tumbuh yang luas tersebut

\footnotetext{
${ }^{1)}$ Undergraduate Student of Study Program of Agrotechnology, Faculty of Agriculture, University of Sebelas Maret UNS) in Surakarta.

${ }^{2)}$ Lecturer of Study Program of Agrotechnology, Faculty of Agriculture, University of Sebelas Maret (UNS) in Surakarta.
}

Contact Author: parjanto.uns@yahoo.co.id diatas memungkinkan terjadinya keragaman atau variasi tanaman. Keragaman pertanaman srikaya tersebut dapat dimanfaatkan sebagai bahan dasar pemuliaan tanaman (Soenarsih et al. 2012). Keragaman pertanaman suatu wilayah dapat diketahui melalui kegiatan karekterisasi atau identifikasi sifat-sifat mofologinya

(Padmini et al. 2013).

Khusus daerah Yogyakarta, sentra penanaman srikaya berpusat di Gedangsari Kabupaten Gunungkidul. Keragaman srikaya pada daerah tersebut belum diketahui secara pasti sehingga perlu studi identifikasi morfologi untuk mempelajari sifatsifat dan keragaman sifat pertanaman srikayadi daerah tersebut. Informasi tersebut berguna untuk studi dan pemanfaatan lebih lanjut terkait pertanaman srikaya di daerah tersebut, baik dalam pelestarian maupun pemanfaatannya dalam kegiatan pemuliaan untuk menghasilkan varietas unggul.

\section{METODE PENELITIAN}

Penelitian dilakukan di Gedangsari, Gunungkidul, Yogyakarta dan Laboratorium Pemuliaan Tanaman Fakultas Pertanian UNS pada bulan September 2012 hingga Maret 2013. Lokasi penelitian merupakan daerah perbukitan dengan ketinggian sekitar \pm 228 mdpl dengan topografi wilayah yang miring, berbatu dan terletak pada $7^{\circ} 48^{\prime} 28,7^{\prime \prime}$ 'LS - 110 $48^{\prime} 52,2^{\prime \prime} B T$. Lokasi penelitian beriklim tropis dengan curah hujan tahun 2012 sebesar $2147 \mathrm{~mm}$ dan 109 hari hujan. Jenis tanah pada lokasi penelitian adalah Litosol 
dengan $\mathrm{pH}$ netral berkisar 6-7.

Bahan penelitian yaitu 36 aksesi tanaman srikaya di Kecamatan Gedangsari, Gunungkidul, Yogyakarta. Alat yang digunakan adalah Jangka sorong, GPS, Klinometer, Altimeter, Hand refraktometer, Roll meter, Timbangan, Kamera Digital, Alat tulis.

Penelitian merupakan penelitian survei untuk mendeskripsikan sifat-sifat morfologi tanaman srikaya di Gedangsari, Gunungkidul, Yogyakarta. Identifikasi dilakukan terhadap 36 tanaman sampel (36 aksesi) yang ditentukan berdasarkan metode stratified sampling dan purposive sampling. Pelaksanaan penelitian melalui tahap-tahap pra survei, penetuan sampel tanaman, identifikasi morfologi, dan pengamatan lokasi geografis.

Analisis data dilakukan secara deskriptif dan dengan metode skor mengacu pada Tjitrosoepomo (2003) dan standar IPGRI (International Plant Genetic Resources Institute). Analisis lanjutan menggunakan analisis cluster untuk mengetahui keragaman aksesi srikaya di Gedangsari. Analisis cluster menggunakan program NTSYS (Numerical Taxonomy and Multivariate System) dengan metode UPGMA (Unweighted Pair Group Method Arithmetic Average) (Rolf 1993). Hasil analisis cluster merupakan persamaan matriks dan disajikan dalam dendogram (Crochemore et al. 2003).

\section{HASIL DAN PEMBAHASAN}

\section{Morfologi Kanopi Tanaman}

Hasil identifikasi morfologi kanopi tanaman pada 36 aksesi pertanaman srikaya menunjukkan bentuk kanopi tanaman piramida dan tinggi tanaman antara $264-525 \mathrm{~cm}$.

\section{Morfologi Daun}

Hasil identifikasi morfologi daun pada 36 aksesi menunjukkan tidak adanya keragaman pada sifat-sifat kualitatif. Daun memiliki tipe daun oblongus, tepi daun integer, bentuk ujung daun acuminatus, pangkal daun acutus, bentuk tangkai daun silindris, warna tangkai daun hijau tua, warna permukaan atas daun hijau tua, warna permukaan bawah hijau pudar. Keragaman terdapat pada sifat-sifat kuantitatif meliputi panjang daun $8,23-16,06 \mathrm{~cm}$, lebar daun $3,73-6,9 \mathrm{~cm}$, dan luas daun $24,28-85,71 \mathrm{~cm}^{2}$.

\section{Morfologi Batang}

Hasil identifikasi morfologi daun pada 36 aksesi pertanaman srikaya menunjukkan tidak adanya keragaman pada bentuk batang yaitu bulat dan pola percabangan yaitu patens. Keragaman terdapat pada lingkar batang yaitu $17,5-38 \mathrm{~cm}$.

\section{Morfologi Bunga}

Hasil identifikasi morfologi daun pada 36 aksesi pertanaman srikaya menunjukkan letak bunga flos axilaris, jumlah mahkota bunga 3 , warna bunga hijau keputihan.

\section{Morfologi Buah}

Hasil identifikasi morfologi buah pada 36 aksesi pertanaman srikaya menunjukkan keragaman yang terdapat pada bentuk buah (round, cordate), berat buah 83,03-180,3 g, lingkar buah 19,36-22,4 cm, tebal daging buah 1,73-3,66 mm, warna kulit buah (hijau keputihan, hijau), jumlah sisik buah 70-104,66 sisik, dan nilai PTT 18-29 ${ }^{\circ}$ brix. Persamaan pada bentuk sisik buah yaitu tumpul.

\section{Morfologi Biji}

Hasil identifikasi morfologi biji pada 36 aksesi tanaman srikaya menunjukkan tidak adanya keragaman pada bentuk biji yaitu ellipsoid. Keragaman terdapat pada jumlah biji 7-70,66 dan berat total biji 2,3-19,86 g.

\section{Pengelompokan Aksesi Srikaya berdasarkan Karakter Morfologi}

Hasil pengamatan dan identifikasi sifat-sifat morfologi 36 aksesi srikaya yang dianalisis berdasarkan analisis cluster sehingga didapat pengelompokkan aksesi sebagaimana disajikan pada gambar dendogram (Gambar 1). Hubungan kekerabatan antar aksesi dapat memberikan informasi tentang ciri khas karakter dari tiap kelompok aksesi yang terbentuk (Hadad et al. 2009).

Dendogram menunjukkan aksesi srikaya memiliki koefisien kemiripan terjauh yaitu 0,66 atau $66 \%$. Analisis dendogram menunjukan tanaman srikaya dapat dihasilkan menjadi 2 kelompok utama. Kelompok pertama terdiri atas aksesi gds4, gds17, gds6, gds23, gds12, gds11, gds31, gds35, gds36, gds13. Kelompok kedua terdiri dari aksesi gds1, gds10, gds2, gds5, gds14, gds32, gds9, gds18, gds8, gds33, gds19, gds29, gds20, gds25, gds21, gds27, gds28, gds34, gds3, gds7, gds15, gds24, gds30, gds16, gds22, gds26. Hasil analisis kemiripan keseluruhan aksesi memiliki kemiripan yang dekat karena koefisiennya kemiripan diatas $60 \%$. Menurut Cahyarini (2004) jarak kemiripan dapat dikatakan jauh apabila kurang dari 0,60 atau $60 \%$. Hasil yang diperoleh merupakan penilaian keragaman genetik dan hubungan antar kultivar (Acosta 2012).

Tingkat kemiripan yang yang tinggi pertanaman srikaya tersebut diduga karena pertanaman srikaya dari jenis yang sama sehingga keragaman jarang dicapai. Keragaman karakter morfologi muncul pada sifat-sifat kuantitatif sedangkan sifat-sifat kualitatif cenderung sama. Hal ini menunjukan adanya pengaruh faktor lingkungan. Suranto (2001) menjelaskan tanaman sejenis akan bervariasi morfologinya apabila faktor lingkungan lebih dominan mempengaruhi daripada faktor genetik. Tanaman tidak akan menunjukkan variasi genetik yang signifikan apabila faktor genetik lebih dominan mempengaruhi tanaman tersebut. Hartl dan Clark (1989) menambahkan tingkat keragaman genetik merupakan suatu indikasi atas kemampuan beradaptasi tanaman terhadap lingkungan tumbuhnya. Jenis tanaman yang mempunyai sebaran alam yang luas akan mempunyai keragaman genetik yang tinggi. variasi antara akses dapat dikaitkan 
dengan riwayat genetik, eko-geografis asal dan seleksi karakter agronomi oleh petani (Chipajola et al. 2009).

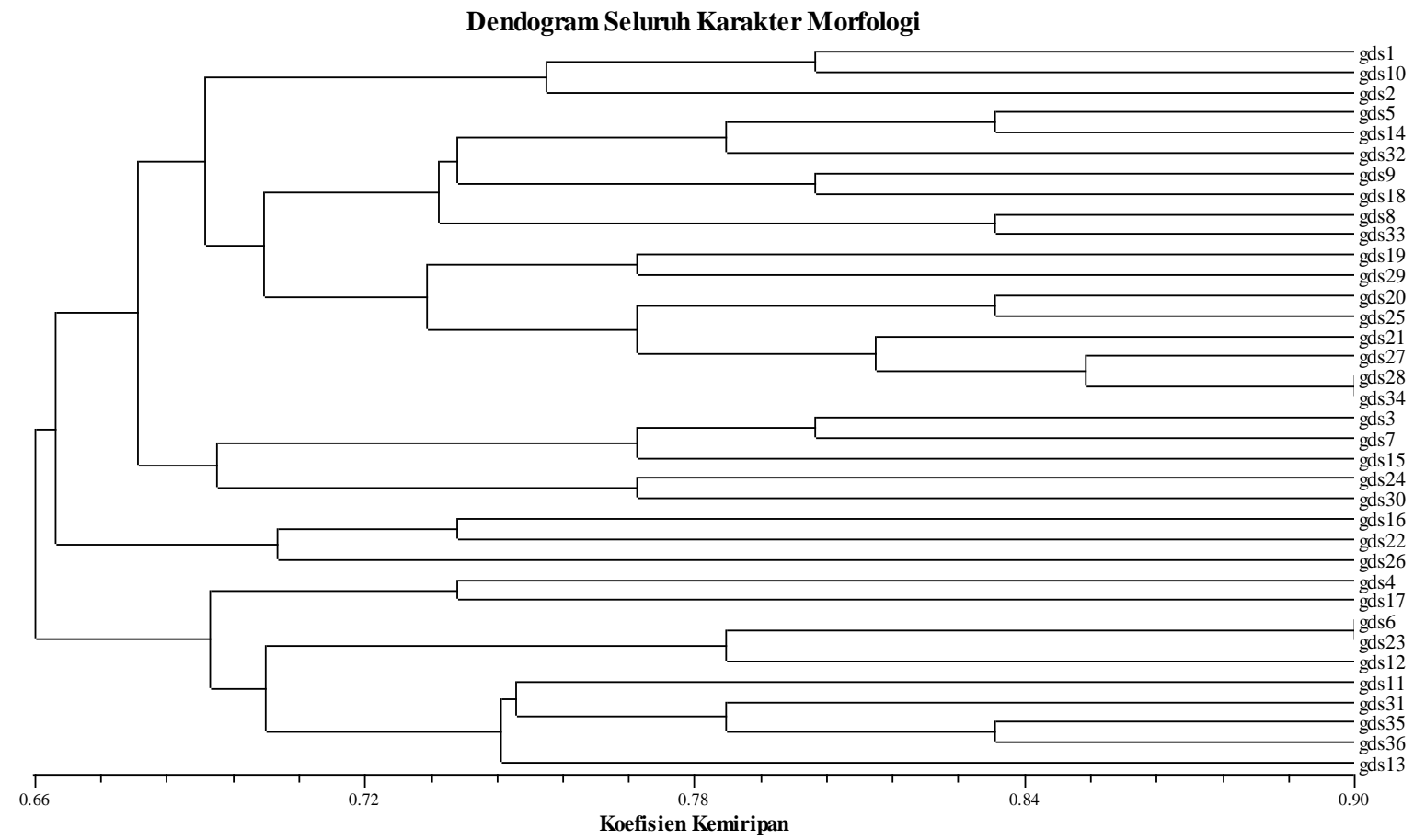

Gambar 1. Dendogram berdasarkan morfologi seluruh variabel srikaya

Pada kelompok pertama aksesi dengan kemiripan tertinggi adalah gds6 dan gds23 dengan tingkat kemiripan 0,90 atau 90\%. Kesamaan kedua aksesi terletak pada bentuk kanopi piramida, bangun daun oblongus, tepi daun integer, bentuk ujung daun acuminatus, pangkal daun acutus, bentuk tangkai daun silindris, warna tangkai daun hijau tua, warna permukaan atas daun hijau tua, warna permukaan bawah hijau pudar, bentuk batang bulat, pola percabangan patens, letak bunga, warna bunga, bentuk buah round, warna kulit buah hijau keputihan, bentuk sisik buah tumpul, bentuk biji yaitu ellipsoid, tinggi tanaman, berat seluruh biji, panjang daun, luas daun, berat buah, lingkar buah, tebal daging buah, jumlah sisik, jumlah biji, berat total biji. Perbedaan karakter terdapar pada lebar daun, lingkar batang, nilai PTT.

Pada kelompok kedua kemiripan tertinggi adalah gds28 dan gds34 dengan nilai kemiripan 90\%. Kesamaan kedua aksesi terletak pada bentuk kanopi piramida, bangun daun oblongus, tepi daun integer, bentuk ujung daun acuminatus, pangkal daun acutus, bentuk tangkai daun silindris, warna tangkai daun hijau tua, warna permukaan atas daun hijau tua, warna permukaan bawah hijau pudar, bentuk batang bulat, pola percabangan patens, letak bunga, warna bunga, bentuk buah round, warna kulit buah hijau keputihan, bentuk sisik buah tumpul, bentuk biji yaitu ellipsoid, tinggi tanaman, berat seluruh biji, panjang daun, lebar daun, luas daun, lingkar batang, berat buah, jumlah sisik, jumlah biji, berat total biji. Perbedaan sifat morfologi terletak pada lingkar buah, tebal daging buah, nilai PTT. Pada kelompok kedua kemiripan tertinggi kedua adalah gds35 dan gds36 dengan jarak 0,83\%. Perbedaan karakter terdapat berat buah, lingkar buah, tebal daging buah, jumlah sisik buah, dan berat total biji.

Kemiripan tinggi pertanaman srikaya di Gedangsari dapat diartikan keragaman genetik antar aksesi rendah. Seluruh aksesi memiliki keragaman yang rendah diduga berasal dari tetua atau bahan tanam yang sama. Seleksi dalam penentuan bahan tanam juga telah dilaksanakan petani walau masih secara sederhana. Biji yang digunakan dalam pembibitan berasal dari buah yang memiliki ukuran yang besar. Srikaya juga merupakan kelompok tanaman penyerbuk sendiri yang ditandai dengan bentuk populasi atau pertanaman yang seragam. Hal inilah yang menyebabkan antar aksesi memiliki variasi sifat-sifat morfologi yang rendah. Variasi genetik tersebut berperan penting dalam program pemulian tanaman (Aharizad et al. 2012). Tresniawati dan Randriani (2011) menjelaskan bahwa karakter dengan keragaman genetik yang luas perlu diperhatikan dalam seleksi untuk mendapatkan tanaman sebagai pohon induk dengan produksi tinggi. Populasi dasar yang memiliki variasi genetik tinggi akan memberikan respon yang baik terhadap seleksi, karena akan memberikan peluang besar untuk mendapatkan kombinasi persilangan yang tepat dengan gabungan sifat-sifat yang baik (Suprapto dan Khairudin 2007). Banyak ragam yang tersedia makin leluasa bagi para pemulia untuk merakit varietas unggul baru (Nandariyah 2009). 


\section{KESIMPULAN DAN SARAN}

Tanaman srikaya di Gedangsari, Gunungkidul, Jogjakarta memiliki bentuk kanopi piramida, tinggi tanaman antara $264-525 \mathrm{~cm}$, tipe daun oblongus, tepi daun integer, bentuk ujung daun acuminatus, pangkal daun acutus, bentuk tangkai daun silindris, warna tangkai daun hijau tua, warna permukaan atas daun hijau tua, warna permukaan bawah hijau pudar. panjang daun antara 8,23-16,06 $\mathrm{cm}$, lebar daun antara 3,73-6,9 cm, luas daun antara 24,28-85,71 $\mathrm{cm}^{2}$, bentuk batang bulat, pola percabangan patens, lingkar batang antara $17,5-38 \mathrm{~cm}$, letak bunga flos axilaris, jumlah mahkota bunga 3 , warna bunga hijau keputihan, bentuk buah round dan cordate, berat buah antara 83,03-180,3 g, lingkar buah antara 19,36$22,4 \mathrm{~cm}$, tebal daging buah antara 1,73-3,66 mm, warna kulit buah hijau keputihan dan hijau, jumlah sisik buah antara 70-104,66 sisik, dan nilai PTT antara 18-29 ${ }^{\circ}$ brix, bentuk sisik buah tumpul, bentuk biji ellipsoid, jumlah biji antara 7-70,66 dan berat total biji antara 2,3-19,86 g.

Keragaman karakter morfologi antar aksesi terdapat pada sifat-sifat kuantitatif meliputi panjang daun, lebar daun, luas daun, lingkar batang, berat buah, lingkar buah, tebal daging buah, jumlah sisik buah, nilai PTT dan sifat-sifat kualitatif meliputi bentuk buah dan warna kulit buah. Analisis pengelompokan berdasarkan seluruh karakter morfologi menunjukan 36 aksesi srikaya memiliki koefisien kemiripan $66 \%$.

\section{DAFTAR PUSTAKA}

Acosta-Quezada PG, Martinez-Laborde JB, Vilanova S, Prohens J. 2012. Genetic diversity and relationships in accessionsfrom different cultivar groups and origins in the tree tomato (Solanum betaceum Cav.). Euphytica (187): 87-97.

Aharizad S, Rahimi MH, Moghadam M, Mohebalipour N. 2012. Study of genetic diversity in lemon balm (Melissa officinalis L.) populations based on morphological traits and essential oils content. Annals Biol Res (12): 5748-5753.

Alex S. 2011. Budidaya dan khasiat srikaya untuk kesehatan dan bisnis makanan. Yogyakarta (ID): Pustaka Baru Press.

Balai Penelitian Tanaman Pangan (BPTP) Jatim. 2011. Plasma Nutfah Durian: Promosi dan usaha pelestarian di Jawa Timur. Warta Plasma Nutfah Indonesia (23): 1-10.

Cahyarini RD, Yunus A, Purwanto E. 2004. Identifikasi keragaman genetik beberapa varietas kedelai lokal di Jawa berdasarkan analisis isozim. Agrosains 6(2): 79-83.

Crochemore ML, Molinari HBC, Vieira LGE. 2003. Genetic diversity in passion fruit (Passiflora spp.) evaluated by RAPD markers. Braz arch biol Tech 46(4): 521-527.

Hadad EA, Andari R, Yudiwanti WEK, Ahmadi NR. 2009. Karakter dan hubungan kekerabatan 27 aksesi pala (Myristica fragrans Houtt.) Di KP Cicurug. Bul RISTRI 1(3): 113-127.
Hartl DL, Clark AG. 1989. Principles of population genetics. Sunderland (USA): Sinauer Inc.

Kementrian Pertanian (Kementan). 2012. Srikaya buah manis dengan manfaat luar biasa. http://epetani.deptan.go.id. Diakses 23 April 2012.

Kementrian Pertanian (Kementan). 2012. Budidaya srikaya. http://epetani.deptan.go.id. Diakses 21 Juni 2012.

Nandariyah. 2009. Peran pemulia dalam participatory plant breeding melalui pemanfaatan sumber daya genetik varietas lokal. Agrosains 11(1): 28-35.

Padmini SPMC, Pushpakumara DKNG, Samarasekera R. 2013. Morphological characterization of soursop (Annona Muricata L.) germplasm in Sri Lanka. Tropic Agri Res 24(4): 362-374.

Rolf FJ. 1993. NTSYS-pc Numerical taxonomic and multivariate analysis system. New York (NY): Exeter Soft Ware.

Soenarsih SDAS, Sudarsono, Djoefrie HMHB, Wahyu YEK. 2012. Keragaman spesies pala (Myristica Spp.) maluku utara berdasarkan penanda morfologi dan agronomi. J Littri 18(1): 1-9.

Suprapto, Khairudin. 2007. Variasi genetik, heritabilitas, tindak gen dan kemajuan genetik kedelai (Glycine max) pada ultisol. J II Pert Ind 9(2): 183-190.

Tjitrosoepomo. 2003. Morfologi tumbuhan. Yogyakarta (ID): Gadjah Mada University Press.

Tresniawati C, Randriani E. 2011. Uji kekerabatan aksesi cengkeh di kebun percobaan Sukapura. Buletin Plasma Nutfah 1(1): 40-45. 